\title{
Aviation medicine?
}

During 1939-49 I carried out five non-funded experimental studies in aviation medicine. The work may conceivably be criticised in that each concerns a series of one case, and all are lamentably lacking in controls.

\section{On a method of improving night vision}

One of the joys of night flying in a suitable aircraft is to do as many upward rolls as possible, with the moon as target; the higher its station, the greater the fun. But a black night-that is another matter. On one such night, the blackest of black nights, for some reason the student and I found ourselves flying inverted. Lo! Whereas previously there had been only a faintly discernible horizon, it was now as clear as if there were a quarter moon. Was this phenomenon reproducible? Indeed it was, and it was many times on that and on other nights.

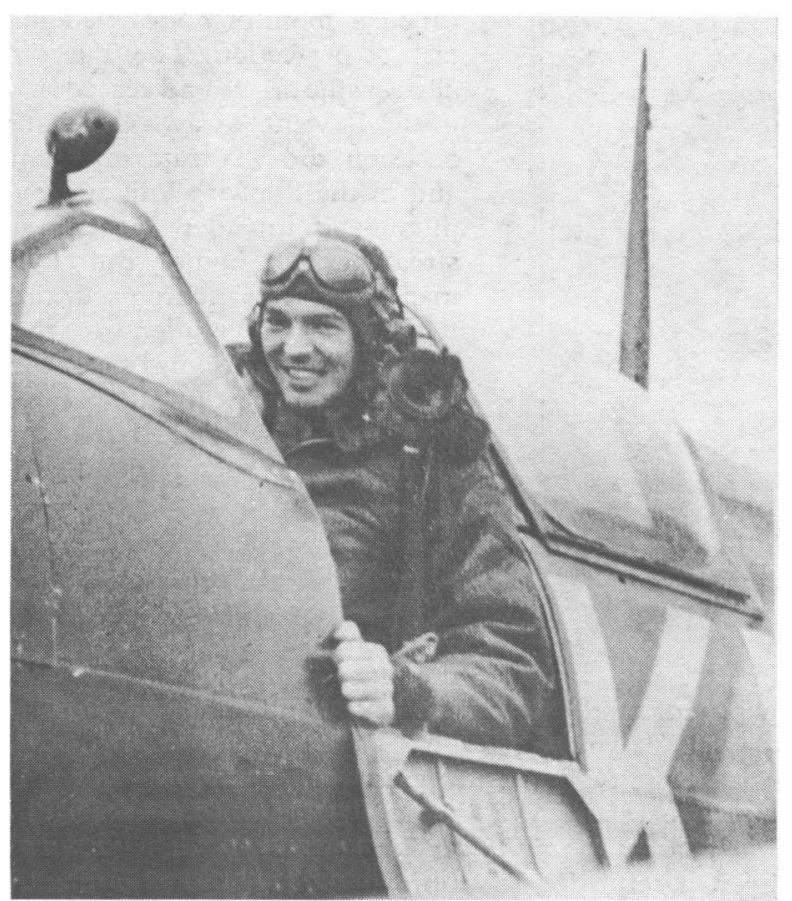

Setting out.

Years later I related this observation to an ophthalmologist who, it so happened, was an Air Force reserve officer. I speculated that the phenomenon was related to increased blood supply either to the visual cortex or to the rods (or cones; I can never quite remember which does which). This intrigued the ophthalmologist, who relayed the tale to an appropriate government agency. A grant, probably quite large, was obtained. The exercises noted above, and I suspect infinite variations thereon,

New London, New Hampshire 03275, USA

W G MACKENZIE HUME, MD, CM, retired paediatrician were carried out. The conclusion inescapably reached was that inverted flight does indeed improve night vision, for one or the other, or both of the reasons put forth above (with no acknowledgment, I may add, to the original observer).

\section{On an impractical method of curing acute torticollis}

Belgium, late September 1944-a glorious autumn day with splendid yellows, browns, and taupes. The haziness, doubtless produced by the war, was pierced regularly by contrails left by V2s aimed at London and Antwerp.

Survival for pilots in war even more than in peacetime is related to their ability to keep a sharp lookout in all anatomically feasible directions. One day, en route to the dispersed aircraft, the squadron jeep hit a large pothole. This induced in me an excrutiating torticollis. A recurring problem, the ordinary time for resolution was seven to ten days. Could one say that a stiff neck made it impossible to carry out the proposed sortie ? I reluctantly thought not, and deeming it advisable, if not very prudent, took off with the squadron on the fighter sweep (fig 1).

An hour later, after landing, I noted with wonder that the torticollis had completely disappeared. There was no pain and, in fact, no residual discomfort whatsoever in this, the most flexible of necks. Which shows how readily one can suppress pain if survival is at stake. In this instance I presume it was the salutory effects of the massive adrenal cortical stimulation induced by finding myself, shortly after take off, in the midst of what seemed an inordinate number of Focke-Wolf 190 s.

\section{On disorientation}

According to my old log books I find that I have done about 40 hours instrument flying, with a similar amount of cloud flying and Link time. The Link was a simulator for teaching the art of blind flying. With the cover in place the student, bathed in the glow of radium tipped instruments, awaited his task, which could be complicated by very rough air (or the simulation of it), as well as by the loss of instruments, singly or in combination, and even a fairly realistic spin after an appropriate stall. I quite like instrument flying and even enjoyed the Link, which was very much to my advantage as will be seen.

One black night, with broken cloud at 800 feet $(243 \mathrm{~m})$, I set out from Annan, Scotland, on a triangular cross country flight. I was flying a Hurricane II. Climbing through cloud at about 1400 feet $(426 \mathrm{~m})$ and off instruments, I looked ahead for the ocean, just to the west. The Merlin engine was running sweetly (why do engines sound better at night and still better on a winter's night?).

A routine check; engine instruments-all in order. Now a look at the blind flying instruments. God! The altimeter was going down through 900 feet $(274 \mathrm{~m})$, the air speed was increasing, the turn needle was fully to the right, the slip indicator was in the centre, the rate of climb indicated full down. Had the aircraft been fitted with an accelerometer it would have shown $1 \mathrm{G}$-that is, no indication either to the seat of the pilot's breeches or to his vestibular apparatus that exitus was imminent.

The time under the hood had been well spent, very well spent indeed. I had been well programmed: the bits, in the computer sense, appropriate-that is, without conscious awareness, or thought, or reflection the turn was stopped, the nose raised, all as full throttle was applied. Recovery height was roughly 
600 feet $(182 \mathrm{~m})$, some 200 feet $(60 \mathrm{~m})$ above the surrounding hills. The cross country flight was completed without further incident.

\section{On accidental hypothermia}

Annan, Dumfriesshire, Scotland-a fighter training station, 1943 (fig 2). Beautiful country, glorious times to be had exploring Burns country by cycle, the Lake country by air. Fresh eggs, nearly unknown further south, were nearly always available at $2 \mathrm{~d}$ to $3 \mathrm{~d}$ apiece. Beautiful, sturdy children abounded, potty (or roadside) trained at an early age, or so it seemed.

A training exercise was scheduled at the local swimming bath to teach us how to manage an inadvertent descent into water during operational or other flying. Such a misfortune, of course, could not happen to our hero. Therefore, claiming a non-existent respiratory infection I did not attend, much to the disgust of the medical officer.

Subsequently on 3 May 1944, my 13th operational trip, the squadron flew off to dive bomb a flying bomb site in France. We orbited and attacked.

The procedure was to identify the site and go into line astern. Each aircraft then, seriatim, rolled over at about 8000 feet $(2430 \mathrm{~m})$ and descended at high speed (there were no dive brakes) with the target in sight. At about 3000 feet $(914 \mathrm{~m})$ the nose was slightly raised-this meant the target was no longer visible-and, holding the angle of dive, the bomb, or bombs (usually one $500 \mathrm{lb}$, occasionally one $500 \mathrm{lb}$ plus two $250 \mathrm{lb}$ ) were released.

I climbed away at a considerably higher rate than the rest of the squadron, as was my custom. Unfortunately, I flew directly into a burst of $88 \mathrm{~mm}$ flak, doubtless aimed at someone else. All seemed normal for a couple of minutes, but subsequently the oil pressure dropped to zero, the engine overheated, the airscrew went into full fine pitch, and it was not possible to shut down the engine. I toyed with the idea of turning into France and attempting to evade capture with the use of appropriate people and my mediocre French. It was, however, rather strongly suggested that I do otherwise. Accordingly, I set course for home. About 10 miles $(16 \mathrm{~km})$ west of Abbeville it became apparent that the aircraft was not going to be airworthy much longer. I decided, therefore, to bail out, but with the original attempt unsuccessful because of excessive speed I sat down again, raised the nose, dropped the speed to about 130 miles $(208 \mathrm{~km})$ an hour, and went head first over the trailing edge of the port wing. After a suitable interval I pulled the rip cord, deploying the parachute. The Spitfire, smoking if not actually in flames, was seen to go straight into the channel, spectacular to observe.

During the descent, which was agreeable enough, certain light housekeeping duties were performed: the stem of the Rolex was carefully tightened and the new 25 shilling lambskin gloves were carefully tucked into the socks.

The temperature of the water was said to have been $40^{\circ} \mathrm{F}$ $\left(5^{\circ} \mathrm{C}\right)$. Dusk was approaching and winds were high. Being unfamiliar with proper procedures, I was dragged a considerable distance by the parachute. When, finally, I squeezed the quick release box the parachute detached, with the dinghy remaining attached to the harness. It hung suspended under the air filled parachute some $20 \mathrm{ft}(6 \mathrm{~m})$ below the surface of the English Channel:

Nightfall approached. Squadron Leader Hartland Finley, RCAF, circled to mark my position until his fuel supply became marginal. Despite the parachute remaining afloat, and the fluorescein marker, my exact position had been lost. Meanwhile, air sea rescue Spitfires appeared. Before leaving, S/L Finley dived low over my presumed position, whereupon the air sea rescue Spitfire dropped dinghies which alas! I did not see. Nor did I see the Spitfires for that matter. Night fell.

Initially there was no awareness of the extreme cold, either at the time of immersion or for some minutes thereafter. This soon passed, however, as did the subsequent shivering. Although medical school was many months in the future I sensed that this sequence of events boded ill, a sense reinforced by the development of a tachypnoea that was quite uncontrollable. Spirits were low, very low indeed.

Then, some 75 minutes after immersion, the silhouette of an air sea rescue Sea Otter appeared. This was a single engined amphibious biplane, boxy and aerodynamically improbable. Despite its sturdiness, the seas were such that even if a safe landing were effected take off would certainly not be possible. The Sea Otter, piloted by Flying Officer Kiwi Saunders,

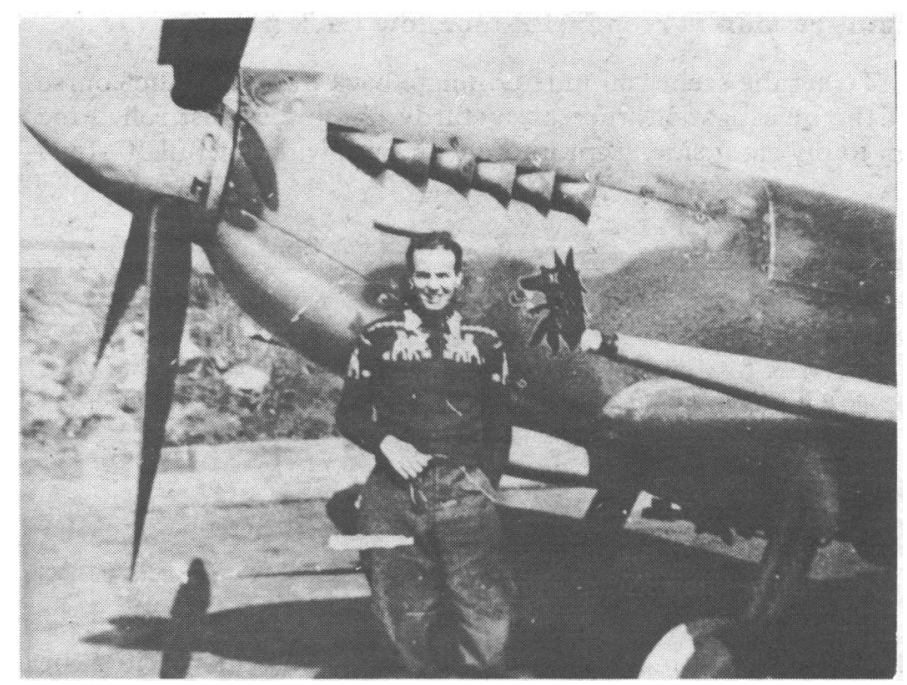

Safely back.

RNZAF, approached, slowly it seemed, and landed with a mighty splash. He had decided to put himself and his crew at almost unwarranted risk. I was aboard within moments.

It may be remembered that one of the infamous experiments carried out by the Third Reich had to do with the improvement of the survival time after cold water immersion. A most effective method of revival was the use of a "gypsy" woman, presumably unclothed, as a source of energy. In the absence of such amenities an RAF flight sergeant undertook to warm me with the heat of his face and of his (clothed) body, surely an act of great compassion and, one may say, love.

Attempts at take off were shudderingly unsuccessful, so we started taxiing towards Dover in heavy seas. The radio was not serviceable. Hours later, a high speed rescue launch sent out on our presumed reciprocal hove into view. As we transferred to it the Sea Otter dug in a wing and promptly sank.

Were we not well received! Towels, dry woollen clothing, and the offer of a very decent brandy, which for the first and I hope last time I was quite unable to face, presumably because of a surfeit of sea water.

We arrived at Dover at about 0300. First activity, a steaming bath, tub filled to the brim (quite against wartime regulations) then bed.

The next morning I was flown in another Sea Otter back to the squadron where I was well received by my squadron mates, although I noted subsequently that drinks for all had been added to my mess bill. This was quite standard practice. I noted, in addition, that two most particular food parcels put together at great expense and with considerable care by my loving spouse had vanished completely-with not so much as a crumb remaining. This was, I thought, questionably standard practice, but understandable when the return of the owner was deemed unlikely.

Cost to His Majesty's government: one Spitfire IXB, one Sea Otter. Cost to me: one pair of very expensive goggles, one 
No 1 uniform, plus the lambskin gloves. And, or course, $f_{1} 10$ s $0 d$ to my parachute rigger, who in retrospect was grossly under-rewarded. My claim to HM government was for the equivalent of $\$ 125$, which an eagle eyed accounts section, in its wisdom, reduced to $\$ 75$.

In 1952 my wife and I returned to Annan. The airfield was difficult to find, and its very existence was apparently not known to the younger inhabitants of the area. We stood there, silently. The wind moaned, the grasses bent, low cloud scudded. We were chilled. Eerie feelings pervaded. We left.

\section{On a method of determining whether vertebral disc compression is responsible for low back pain}

To set the scene: an indeterminate back injury. In the course of the investigation, thereof, a sturdy physiotherapist rolled me on to my right side, leapt into the air, and with her full 10 stone
(63 kg) distributed across a muscular forearm, came down from above on my haunch with the production of (to her) a most satisfactory and resounding crack. To me this boded ill, but in order to escape I readily agreea that I indeed "felt much better."

Discharged from hospital 10 weeks later, worried whether I would be able to complete my final year of medical school and still uncomfortable, what was a medical student to do? No diagnosis had been established, though iatrogenesis-a newly learnt term-suggested itself.

Accordingly, on my next flying weekend I went to the RCAF station at Saint Hubert, Quebec, boarded a trusty DeHavilland Vampire, fired up, took off, and climbed to 15000 feet (4572 m). Rolling inverted (not, this time, to improve vision) I descended at high speed, imposing on pullout 6-8 $\mathrm{G}$ to my unprotesting intervertebral spaces. This was repeated. No pain, referred or otherwise. Ergo, no disc problem. Subsequently, aging sacroiliac joints spontaneously fused, resolving the difficulty.

\title{
Letter from Eritrea
}

\author{
JOHN BLACK
}

The recently formed Eritrean Medical Association invited me to attend their first congress, which was held at Orota Base Hospital in Eritrea. As Eritrea has no official existence as a country, and its war for independence from Ethiopia, now in its 22nd year, receives little attention from the news media, it is not surprising that my intended visit had produced comments ranging from complete ignorance of Eritrea's existence, to praise for its bird watching facilities.

The journey by Toyota Land Cruiser from Port Sudan was a 12 hour overnight agony of bumping from rut to rut, or rock to rock, according to the terrain. The only diversions were a stop for tea at a group of trees in the desert where a nomad family brewed tea with cloves on a charcoal fire, and a meal of goat stew at one of the very impressive "garage" enclosures where the Eritreans service the trucks which bring in their supplies. In the desert area the headlights picked out groups of antelope, and in the lowland hills we passed numerous camels which clumped witlessly along in front of the truck; once we passed a large herd of about 200 camels with their young.

The hospital where the congress took place has about 800 patients and extends for about $6 \frac{1}{2} \mathrm{~km}$ (four miles) along a steeply sided rocky valley. Nomad families with their camels and goats pick their way among the walking patients, the head of the family in front, with a large "crusader" type of sword on a belt and a goatherd's stick held across the nape of his neck. The wards and departments are cut out of the mountainside and their projecting walls and roofs are hidden from the air by living thorn trees or cut branches. The patients, apart from those who are seriously ill, lie on blankets on the stony ground. Convalescent patients receive regular educational or literacy classes. All operations are done at night, when the generator is running, to conserve fuel. The standard of surgery and anaesthesia is high, and the work of the maxillofacial unit, in the charge of a woman surgeon who trained in Sofia, is particularly impressive. Apart

King's College Hospital, London

JOHN BLACK, MD, FRCP, honorary consultant paediatrician from the usual specialist departments there is a modern plant which produces intravenous fluids, a small library, and a department for the translation of medical journals and papers and the production of instructional leaflets for nurses and health workers. In a neighbouring valley there is an information department with printing presses, where the first two numbers of the Eritrean Medical fournal have already been produced. There is a large rehabilitation unit where the blind are taught to play musical instruments, and other disabled patients are taught wood and metal working, watch repairing, car maintenance, and art. Orota hospital is better equipped than the smaller ones, which are desperately short of equipment and trained staff. Food is barely sufficient and consists almost entirely of "injera," a form of flat bread made from sorghum, a type of millet, supplemented by small amounts of dried skimmed milk and occasional green peppers; meat is completely absent from the diet. There is a permanent shortage of drugs, medical equipment, and $x$ ray film.

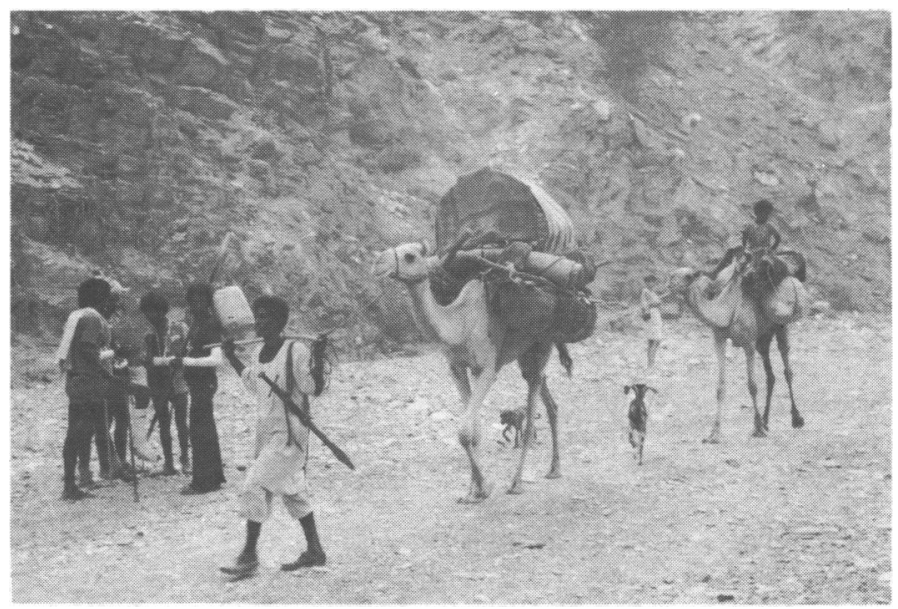

A nomad family passing through the hospital valley; the women travel in the tent on the back of the camel. 